\title{
Vulnerable Trade: The Dark Side of an Edgeworth Box
}

\author{
Charles H. Anderton \\ and \\ John R. Carter
}

July 2004

\section{COLLEGE OF THE HOLY CROSS, DEPARTMENT OF ECONOMICS FACULTY RESEARCH SERIES, WORKING PAPER NO. 04-11*}

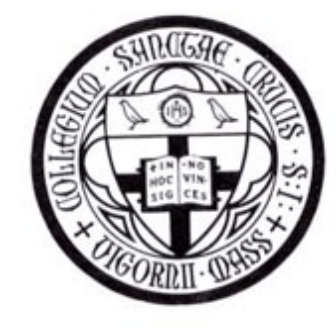

Department of Economics

College of the Holy Cross

Box 45A

Worcester, Massachusetts 01610

(508) 793-3362 (phone)

(508) 793-3710 (fax)

http://www.holycross.edu/departments/economics/website

*All papers in the Holy Cross Working Paper Series should be considered draft versions subject to future revision. Comments and suggestions are welcome. 


\title{
Vulnerable Trade: The Dark Side of an Edgeworth Box
}

\author{
By \\ Charles H. Anderton ${ }^{\dagger}$ \\ College of the Holy Cross \\ and \\ John R. Carter ${ }^{\dagger+}$ \\ College of the Holy Cross
}

July 2004

\begin{abstract}
We examine incentives to seize and defend goods offered for trade in an Edgeworth box economy. Appropriation possibilities generate an equilibrium of coerced redistribution and voluntary trade in a reduced box. Potential mutual gains remain untaken because the prospect of piracy creates a price wedge, wherein the effective relative price is lowered for the exporter and raised for the importer. As the vulnerability of one or both goods increases, the price wedge widens, causing trade to diminish. If vulnerability becomes sufficiently high, then trade and appropriation are driven to zero, or one or both players are rendered indifferent to trade.
\end{abstract}

JEL Classification Codes: C72, D51, D74, F10

Keywords: Edgeworth box, piracy, trade

${ }^{\dagger}$ Charles H. Anderton, Department of Economics, Box 85A, College of the Holy Cross, Worcester, MA 01610-2395, 508-793-3441 (phone), 508-793-3710 (fax), canderto@holycross.edu

${ }^{\dagger \dagger}$ John R. Carter, Department of Economics, Box 147A, College of the Holy Cross, Worcester, MA 01610-2395, 508-793-2676 (phone), 508-793-3710 (fax), jcarter@holycross.edu 
The Edgeworth box, simple as it is, is remarkably powerful. There are virtually no phenomena or properties of general equilibrium exchange economies that cannot be depicted in it (Mas-Colell et al., 1995, 521).

[I]t may be assumed that very shortly after men began the transport of goods from one point to another various enterprising individuals arose who saw profit in intercepting these goods on the way (Gosse, $([1932] 1968,1)$.

\section{INTRODUCTION}

Central to the field of conflict economics is the premise that appropriation stands coequal with production and trade as a fundamental category of economic activity. In the words of Hirshleifer's $(1994,2)$ presidential address before the Western Economic Association:

... the mainline Marshallian tradition has ... almost entirely overlooked what I will call the dark side of the force....[S]ure, you can produce goods for the purpose of mutually beneficial exchange with other parties - OK, that's Marshall's “ordinary business." But there's another way to get rich; you can grab goods that someone else has produced. Appropriating, grabbing, confiscating what you want - and, on the flip side, defending, protecting, sequestering what you already have - that's economic activity too.

Resource allocations to appropriation and defense fundamentally affect the acquisition and retention of wealth. Moreover, production, trade, and relative prices are reshaped by appropriation in ways that are generally ignored in mainstream economics.

Appropriation possibilities are part of the everyday human condition. This is most obvious in less developed economies experiencing tyranny, corruption, criminal syndicates, or civil war. In such settings insecure property rights create strong incentives for appropriation and defense. For example, traders who bring their goods to market must allocate resources to protect their goods along the way. If trade is sufficiently vulnerable to appropriation, would-be traders may find that autarky is the better option. More generally, appropriative struggles in insecure 
economies redistribute wealth, reduce consumption, diminish investment, and dampen specialized production and trade, as documented in Collier et al. (2003). Even in economies with ostensibly secure property rights, appropriation possibilities pervade economic life. Electronic and video security systems; piracy of music, software, and motion pictures; and common theft are but a few examples of appropriation possibilities at work in modern economies. Even a commonplace vending machine is, upon closer look, a sophisticated piece of defense capital designed to induce exchange rather than appropriation.

Economists have begun to incorporate Hirshleifer's dark side of behavior into mainstream general equilibrium models of economic activity. The common theme linking these models is that appropriation activity is costly in terms of forgone production and/or exchange. Also common is the use of contest success functions whereby appropriative outcomes are determined by competing resources and conflict technology. The models differ primarily with respect to which categories of economic activity are considered. In this regard, conflict models fall into three groups. Perhaps best known are models that combine production and appropriation; other models include exchange and appropriation; and a few models allow all three activities. ${ }^{1}$

We present a model of vulnerable trade which, as the name suggests, focuses on the interaction of exchange and appropriation and hence falls in the second group of conflict models above. Our starting point is a standard Edgeworth box, notable for its relative simplicity and widespread recognition among economists. We introduce appropriation opportunities by assuming that while endowments are secure, goods are vulnerable to appropriation once offered for trade. Beginning from a situation of secure trade, we ask what are the economic effects of increased vulnerability of one or both goods. Our model is differentiated from most others in that we assume traded goods rather than endowments are subject to appropriation; we permit the 
degree of vulnerability to differ between goods; and we show that vulnerability can generate autarky as an equilibrium outcome. ${ }^{2}$

\section{A MODEL OF VULNERABLE TRADE}

\section{$\underline{\text { General Model }}$}

As in the classical Edgeworth box, we assume two players $A$ and $B$ with well-behaved preferences over two goods $X$ and $Y$. The players can be individuals or groups (including countries). Initial endowments $E_{i}^{X}$ and $E_{i}^{Y}(i=A, B)$ are such that if trade occurs, $A$ will import $X$ and export $Y$. Goods designated for trade are subject to appropriation and are called gross exports. Exports remaining after appropriation are exchanged at Walrasian market prices $P^{X}$ and $P^{Y}$ and are called realized exports. ${ }^{3}$ For simplicity, we assume each good is attacked and defended out of initial endowments of that same good. To follow the notation, think of $h$ as height of fortification and $g$ as guns used for attack. Then Player $A$ diverts $g_{A}^{X}$ of its $X$ endowment toward the appropriation of $B$ 's gross exports of $X$, which $B$ protects by diverting $h_{B}^{X}$ of its $X$ endowment to defensive effort. Likewise, $B$ allocates $g_{B}^{Y}$ of its $Y$ endowment toward the appropriation of A's gross exports, while $A$ allocates $h_{A}^{Y}$ of its $Y$ endowment to protect them.

Appropriation possibilities over traded goods are determined by a contest success function wherein the proportion of gross exports realized in exchange depends on the levels of fortification and defense together with a good-specific vulnerability parameter $Z^{j}(j=X, Y)$ :

$$
\begin{aligned}
& r_{A}^{Y}=f\left(h_{A}^{Y}, g_{B}^{Y}, Z^{Y}\right) \text { with } 0 \leq r_{A}^{Y} \leq 1, f_{1}>0, f_{2}<0, f_{3}<0, f_{11}<0, f_{22}>0 \\
& r_{B}^{X}=f\left(h_{B}^{X}, g_{A}^{X}, Z^{X}\right) \text { with } 0 \leq r_{B}^{X} \leq 1, f_{1}>0, f_{2}<0, f_{3}<0, f_{11}<0, f_{22}>0 .
\end{aligned}
$$

In equation (1), the proportion of $A$ 's gross exports of $Y$ not appropriated by $B$ and hence realized by $A$ is $r_{A}^{Y}$. This proportion varies directly with $A$ 's defensive effort $h_{A}^{Y}$, inversely with $B$ 's 
appropriation effort $g_{B}^{Y}$, and inversely with good $Y^{\prime}$ s vulnerability $Z^{Y}$. Equation (2) shows the analogous retention rate $r_{B}^{X}$ for $B$ 's gross exports of $X$. The proportion of $A$ 's gross exports appropriated by $B$ is then $\left(1-r_{A}^{Y}\right)$, while the proportion of $B$ 's gross exports appropriated by $A$ is $\left(1-r_{B}^{X}\right)$. Without loss of generality, we assume $Z^{Y} \geq Z^{X}$, such that good $Y$ is at least as vulnerable as good $X$.

Turning to player $A$ 's optimization problem, recall that $A$ imports good $X$ and exports good $Y$. A's consumption expenditures equal $P^{X} X_{A}+P^{Y} Y_{A}$. Under vulnerable trade, $A^{\prime}$ s disposable income is the value of initial endowments net of resources diverted for conflict, plus any $X$ seized in trade from $B$, and minus any $Y$ seized in trade by $B$. A's endowment of $X$ net of resources employed to seize $X$ is $E_{A}^{X}-g_{A}^{X}$. B's gross exports of $X$ are $E_{B}^{X}-h_{B}^{X}-X_{B}$, of which A seizes the proportion $\left(1-r_{B}^{X}\right)$. A's endowment of $Y$ net of resources used to protect its exports of $Y$ is $E_{A}^{Y}-h_{A}^{Y}$. Its gross exports are $E_{A}^{Y}-h_{A}^{Y}-Y_{A}$, of which $A$ loses the proportion $\left(1-r_{A}^{Y}\right)$. Equating expenditures to disposable income and dividing through by $P^{Y}$ yields A's budget constraint, where $P \equiv P^{X} / P^{Y}$ denotes the world relative price of $X$ :

$$
P X_{A}+Y_{A}=P\left[E_{A}^{X}-g_{A}^{X}+\left(E_{B}^{X}-h_{B}^{X}-X_{B}\right)\left(1-r_{B}^{X}\right)\right]+\left[E_{A}^{Y}-h_{A}^{Y}-\left(E_{A}^{Y}-h_{A}^{Y}-Y_{A}\right)\left(1-r_{A}^{Y}\right)\right] .
$$

Solving (3) for $X_{A}$ leads to:

$$
X_{A}=E_{A}^{X}-g_{A}^{X}+\left(E_{B}^{X}-h_{B}^{X}-X_{B}\right)\left(1-r_{B}^{X}\right)+(1 / P)\left(E_{A}^{Y}-h_{A}^{Y}-Y_{A}\right) r_{A}^{Y} .
$$

Assuming Cournot/Nash behavior, $A$ 's maximization problem is:

$$
\max _{Y_{A}, h_{A}^{Y}, g_{A}^{X}} U\left[X_{A}\left(Y_{A}, h_{A}^{Y}, g_{A}^{X}\right), Y_{A}\right],
$$

where the function $X_{A}\left(Y_{A}, h_{A}^{Y}, g_{A}^{X}\right)$ is defined by (4). 
The first-order conditions for an interior solution to (5) are:

$$
\begin{array}{ll}
-U_{X_{A}}(1 / P) r_{A}^{Y}+U_{Y_{A}}=0 & \Rightarrow\left(U_{X_{A}} / U_{Y_{A}}\right)=\left(P / r_{A}^{Y}\right) \\
U_{X_{A}}(1 / P)\left[\left(E_{A}^{Y}-h_{A}^{Y}-Y_{A}\right)\left(\partial r_{A}^{Y} / \partial h_{A}^{Y}\right)-r_{A}^{Y}\right]=0 \Rightarrow\left(E_{A}^{Y}-h_{A}^{Y}-Y_{A}\right)\left(\partial r_{A}^{Y} / \partial h_{A}^{Y}\right)=r_{A}^{Y} \\
U_{X_{A}}\left[\left(E_{B}^{X}-h_{B}^{X}-X_{B}\right)\left(\partial\left(1-r_{B}^{X}\right) / \partial g_{A}^{X}\right)-1\right]=0 \Rightarrow\left(E_{B}^{X}-h_{B}^{X}-X_{B}\right)\left(\partial\left(1-r_{B}^{X}\right) / \partial g_{A}^{X}\right)=1 .
\end{array}
$$

Equations (6)-(8) capture the key tradeoffs for player $A$ in the vulnerable trade model.

Equation (6) shows that consumption is extended to the point where the marginal rate of substitution between $X_{A}$ and $Y_{A}$ equals the effective relative price of $X$, which is $P / r_{A}^{Y}$. To understand the effective price, suppose the world relative price of $X$ is $P=1$ and $A$ 's retention ratio is $r_{A}^{Y}=0.5$. In order to import an additional unit of $X, A$ will have to divert $2 Y$ from consumption and make it available for export. Half of the $2 Y$ will be appropriated, leaving as realized exports $1 Y$ exchanged for the unit of $X$. Hence, the opportunity cost to $A$ for a unit of $X$ is $P / r_{A}^{Y}=1 / 0.5=2 Y$. In the special case of classical trade, appropriation is impossible, $r_{A}^{Y}=1$, and equation (6) reduces to the standard optimization condition. With vulnerable trade, $r_{A}^{Y}$ falls below 1, such that $A$ 's effective price of $X$ is raised above the world price, thus discouraging $A$ 's imports and consumption of $X$.

Equation (7) shows how A utilizes resources to defend its gross exports of $Y$. Defensive effort $h_{A}^{Y}$ is extended to the point where the additional exports realized equal the incremental exports forgone through the drain of resources for protection. Exports realized and exports forgone due to the marginal unit of fortification are $\left(E_{A}^{Y}-h_{A}^{Y}-Y_{A}\right)\left(\partial r_{A}^{Y} / \partial h_{A}^{Y}\right)$ and $r_{A}^{Y}$. Hence, equation (7) balances the marginal benefits and marginal costs of using resources for export defense. 
Equation (8) shows how $A$ utilizes resources to attack B's gross exports of $X$. Appropriation effort $g_{A}^{X}$ is extended to the point where the increment in $M$ seized equals the amount of $M$ lost through the drain of resources for attack. Marginal $X$ appropriated and marginal $X$ lost from the allocation of resources to attack are $\left(E_{B}^{X}-h_{B}^{X}-X_{B}\right)\left(\partial\left(1-r_{B}^{X}\right) / \partial g_{A}^{X}\right)$ and 1. Hence, equation (8) balances the marginal benefits and marginal costs of using resources to attack B's gross exports.

Similar modeling applies to player $B$, who faces an effective relative price of $X$ equal to $\operatorname{Pr}_{B}^{X}$. To continue the example above, suppose $P=1$ and $r_{B}^{X}=0.5$. When $B$ diverts from consumption a unit of $X$ for export, half will be appropriated, leaving $0.5 X$ as realized exports exchanged for $0.5 Y$. Hence, $B$ 's effective price for a unit of $X$ is $\operatorname{Pr}_{B}^{X}=1(0.5)=0.5 Y$. Notice that when $r_{B}^{X}$ falls below 1 with vulnerable trade, $B$ 's effective price of $X$ is lowered below the world price, thus discouraging $B$ 's export and encouraging $B$ 's consumption of $X$.

From the above we obtain six first-order conditions and two budget constraints that together define the optimal consumption levels and resource allocations for players $A$ and $B$. We close the system with a price equation whereby the value of $A$ 's realized exports equals the same for $B$ : (9) $P^{Y}\left(E_{A}^{Y}-h_{A}^{Y}-Y_{A}\right) r_{A}^{Y}=P^{X}\left(E_{B}^{X}-h_{B}^{X}-X_{B}\right) r_{B}^{X} \Rightarrow P=\left(E_{A}^{Y}-h_{A}^{Y}-Y_{A}\right) r_{A}^{Y} /\left(E_{B}^{X}-h_{B}^{X}-X_{B}\right) r_{B}^{X}$ The nine equations are assumed to define a Nash equilibrium in $X_{A}, Y_{A}, h_{A}^{Y}, g_{A}^{X}, X_{B}, Y_{B}, h_{B}^{X}, g_{B}^{Y}$, and $P$.

\section{Graphical Illustration with Complete Symmetry}

Figure 1 illustrates how the economic landscape is changed when appropriation opportunities are introduced in an Edgeworth box economy. We invoke several assumptions which together constitute what we call complete symmetry. We begin by assuming that players $A$ and $B$ have equal cross endowments $\left(E_{A}^{X}=E_{B}^{Y}\right.$ and $\left.E_{A}^{Y}=E_{B}^{X}\right)$. This gives rise to a square Edgeworth box 
and an initial endowment point at $a$ on the off-diagonal. We assume that the preferences of $A$ and $B$ are identical and homothetic, thus generating a linear contract curve. We also assume that the two goods are weighted equally in the utility function $\left(\left.M R S\right|_{X=Y}=1\right)$. The equal weight assumption, identical preferences, and a square Edgeworth box imply that the absolute value of the slope of the off-diagonal is the relative world price (or terms of trade) of $X$ and equals one $\left(P=P^{X} / P^{Y}=1.0\right)$. Player $A$ imports $a m$ units of good $X$ and exports $m e$ units of good $Y$ (with $B$ the other side of the trade), and equilibrium consumption occurs at point $e$.

Now assume that exports of each good are equally vulnerable to appropriation with $Z^{X}=Z^{Y}$. Given the symmetry assumptions above, each player will allocate an equal amount of resources to defense of exports $\left(h_{A}^{Y}=h_{B}^{X}=h\right)$ and attack of imports $\left(g_{A}^{X}=g_{B}^{Y}=g\right)$. Resources allocated to attack and defense are not available for consumption. Hence, the Edgeworth box shrinks by $h+g$ along each dimension, giving rise to the dashed box shown in Figure 1. The drain of resources for attack and defense also shifts the endowment point from $a$ to $b$ in the figure. Under the symmetry assumptions, point $b$ will lie on the off-diagonal of the reduced Edgeworth box. Because the upper and right boundaries of the reduced box constitute the effective axes for player $B, B$ 's indifference curves also shift relative to the original Edgeworth box. The shrinkage of the Edgeworth box is the resource cost effect of appropriation possibilities and is determined endogenously in the model.

The two basic activities of appropriation and exchange combine to determine final consumption at point $d$ in Figure 1. Appropriation of traded goods moves the economy from $b$ to $c$, while realized exchange carries the economy from $c$ to $d$. Player A's gross exports of good $Y$ encompass $b j$ units seized by $B$ together with $c k$ units successfully exchanged. Under symmetry, the same amounts apply to player $B$ for good $X$. Because point $d$ lies on the off- 
diagonal of the reduced box, players $A$ and $B$ have equal cross consumptions and $P$ remains equal to 1.0. We define a good's piracy rate as the percentage of a player's gross exports that are appropriated, which is $100 * b j /(b j+c k)$ in Figure 1. We define a good's trade destruction rate as the percentage decline of a player's realized exports relative to exports in a classic Edgeworth box economy, which is $100 *(m e-c k) / m e$ in Figure 1. The piracy and trade destruction rates (and thus the location of points $c$ and $d$ on the new off-diagonal) are determined endogenously.

Notice in Figure 1 that a region of mutual gain remains at the final consumption point $d$. This is due to the wedge effect of appropriation possibilities whereby the relative prices of $X$ observed by $A$ and $B$ fail to converge. At point $d$, the players' marginal rates of substitution equal their corresponding effective relative prices of $X$. Hence, player A's marginal rate of substitution at point $d$ is $P / r_{A}^{Y}=1 / r_{A}^{Y}$. Even though player $A$ 's marginal valuation of $X$ is greater than the world price, $A$ is indifferent to importing a marginal unit of $X$ at a price of 1.0 because of anticipated piracy. Given the piracy rate for $Y$, in order to finance the import of a unit of $X, A$ would have to make available for export $P / r_{A}^{Y}$ units of $Y$, which is just equal to $A$ 's subjective value of $X$ in consumption. On the other side, player $B$ is indifferent to exporting a marginal unit of $X$ at a contractual price of 1.0, because given the piracy of $X, B$ would realize as net payment only $\operatorname{Pr}_{B}^{X}$ units of $Y$, just equal to $B$ 's subjective value of $X$ in consumption. In summary, the divergent effective prices discount for anticipated piracy and thereby restrain trade.

Figure 1 also demonstrates the utility losses associated with the resource cost and wedge effects of appropriation possibilities. Focusing on player $A$, the decline in utility from $U_{2}$ to $U_{1}$ is due to the resource cost effect. The additional decline in utility, from $U_{1}$ to $U_{0}$, is associated with the wedge effect. Given symmetry, the same utility losses hold for player $B$. 
Lastly, note that Figure 1 implies that each player prefers vulnerable trade to autarky. Player A's indifference curve through point $d$ is higher than A's indifference curve through point $a$. Hence, player $A$ (and by symmetry, player $B$ ) prefers vulnerable trade to autarky $\left(U_{0}>U_{a}\right)$. However, if appropriation possibilities are sufficiently strong, the resource cost and wedge effects could result in indifference curve $U_{0}$ lying below the indifference curve through point $a$. In this case autarky would be the equilibrium prediction of the vulnerable trade model.

\section{EXAMPLES OF VULNERABLE TRADE}

\section{$\underline{\text { Additional Assumptions }}$}

As noted in the introduction, our primary focus is on the economic effects of increased vulnerability of one or both goods. To explore the comparative statics, we begin by operationalizing the symmetry assumptions of the illustration above. Specifically, we assume that players $A$ and $B$ have an identical constant elasticity of substitution (CES) utility function $U=\left(X^{\rho}+Y^{\rho}\right)^{1 / \rho}$. Hence, preferences are homothetic with a marginal rate of substitution of unity given equal amounts of $X$ and $Y$. The CES function has an elasticity of substitution $\sigma$ equal to $1 /(1-\rho)$ and converges to a Cobb-Douglas function $U=X^{1 / 2} Y^{1 / 2}$ for $\rho=0$. As above, we assume that $A$ and $B$ hold equal cross endowments such that the initial endowment point lies on the cross diagonal of a square Edgeworth box.

Throughout the examples we assume ratio-form contest success functions:

$$
\begin{aligned}
& r_{A}^{Y}=h_{A}^{Y} /\left(h_{A}^{Y}+Z^{Y} g_{B}^{Y}\right) \\
& r_{B}^{X}=h_{B}^{X} /\left(h_{B}^{X}+Z^{X} g_{A}^{X}\right)
\end{aligned}
$$

with $Z^{Y} \geq Z^{X}$. If no resources are allocated to defense or attack of a traded good, then its retention ratio is defined as unity, and there is no appropriation. The vulnerability parameters $Z^{X}$ and $Z^{Y}$ are determined exogenously and reflect the relative effectiveness of attack versus defense 
effort. For example, if $Z^{j}$ equals 2 , then the technology of conflict is such that attack effort is twice as effective as defense effort. When the vulnerability parameters are equal, we denote their common value by $Z{ }^{4}$

As noted above, we refer to the case of identical homothetic preferences with equal cross endowments and equal vulnerability parameters as complete symmetry. The resulting equilibrium is characterized by equal cross consumptions $\left(X_{A}=Y_{B}\right.$ and $\left.Y_{A}=X_{A}\right)$, defense efforts $\left(h_{A}^{Y}=h_{B}^{X}\right)$, and attack efforts $\left(g_{A}^{X}=g_{B}^{Y}\right)$, together with a world relative price of 1.0 . In the Appendix we present an explicit reduced-form solution for the case of complete symmetry with CES utility functions and ratio-form contest success functions. Unfortunately, the solution is unwieldy. Hence, below we explore the comparative statics of vulnerable trade through a series examples solved independently by numerical methods. ${ }^{5}$

\section{Base Case with Complete Symmetry}

Figure 2 is constructed assuming complete symmetry with Cobb-Douglas preferences and with initial endowments $\left(E_{A}^{X}, E_{A}^{Y}\right)=(100,800)$ and $\left(E_{B}^{X}, E_{B}^{Y}\right)=(800,100)$. The example constitutes the base case when we explore comparative statics in subsequent examples.

In the classic Edgeworth box, trade is secure with $Z$ equal to 0 . Mutual gains accrue when $A$ and $B$ trade from the initial endowment point $a$ to the final consumption point $e$ at the world relative price $P=1.0$. Player $A$ imports 350 units of $X$ and exports 350 units of $Y$, with $B$ on the opposite side of trade. Each player consumes 450 units of each good and enjoys an increase in utility from 282.8 (equal to $100^{1 / 2} 800^{1 / 2}$ ) under autarky to 450.0 with trade.

Appropriation possibilities are introduced by increasing $Z$ to 0.5 . The arrow in the top right of Figure 2 shows how the dimensions of the Edgeworth box shrink when resources are drained in the defense and attack of trade. The upper and right boundaries of the reduced box are shown 
with bold dashed lines. Because these two boundaries constitute the effective axes for player $B$, $B$ 's indifference curves shift relative to the original Edgeworth box. The dimensions of the reduced box are determined endogenously by the players' defense and attack choices. In equilibrium, player $A$ allocates $h_{A}^{Y}=75.1$ units of its $Y$ endowment to defend its gross exports and $g_{A}^{X}=55.0$ units of its $X$ endowment to attack $B$ 's gross exports. Player $B$ defends and attacks at equal levels of the opposite endowments. Due to these resource costs, the effective endowment point shifts from $a$ to $b$, reducing holdings for $A$ and $B$ to $(45.0,724.9)$ and $(724.9,45.0)$. As the players allocate resources to defense and appropriation of trade, the aggregate economy suffers a resource cost of 130.1 units of each good.

Appropriation and exchange together determine final consumption at point $d$ in Figure 2 with $\left(X_{A}, Y_{A}\right)=(325.4,444.5)$ and $\left(X_{B}, Y_{B}\right)=(444.5,325.4)$. Appropriation pushes the economy from point $b$ to $c$, while exchange allows it to move from $c$ to $d$. Player A's gross exports of $Y$ encompass 75.1 units seized by $B$ together with 205.3 units successfully exchanged. The same numbers apply to $B$ for good $X$. Hence, the piracy rates of $X$ and $Y$ are each $26.8 \%$ (equal to $75.1 /(75.1+205.3)$, or equivalently $\left.1-r_{i}^{j}=1-0.732\right)$. Recall that secure trade generates exports of 350 units of each good, whereas vulnerable trade here yields realized exports of 205.3 units of each. Hence, the trade destruction rate in Figure 2 for each good is $41.3 \%$ (equal to (350205.3)/350).

A region of mutual gain remains at the final consumption point $d$ due to the wedge effect whereby the players' effective relative prices of $X$ fail to converge. At the final equilibrium the effective relative prices of $X$, and hence the corresponding marginal rates of substitution, are $P_{A}=1.366$ (equal to $P / r_{A}^{Y}=1 / 0.732$ ) and $P_{B}=0.732$ (equal to $\operatorname{Pr}_{B}^{X}=1 \cdot 0.732$ ). Player $A$ is indifferent to importing a marginal unit of $X$ at a price of 1.0, because given the piracy rate for $Y$, 
$A$ would have to make available for export 1.366 units of $Y$, just equal to $A$ 's subjective value of $X$ in consumption. On the other side, player $B$ is indifferent to exporting a marginal unit of $X$ at a contractual price of 1.0 , because given the piracy rate for $X, B$ would receive as net payment only 0.732 units of $Y$, just equal to $B$ 's subjective value of $X$ in consumption.

The model of vulnerable trade assumes that only traded goods are subject to appropriation and that each player may consume his or her full initial endowment in autarky. Hence, mutual gains are assured on any realized voluntary trade. Between the initial endowment point $a$ and the final consumption point $d$, each player's utility increases from 282.2 in autarky to 380.3 (equal to $325.4^{1 / 2} 444.5^{1 / 2}$ ) under appropriation and trade. At the same time, due to the resource cost and wedge effects, utilities fall well short of the 450.0 that would be enjoyed in the classic Edgeworth box economy. ${ }^{6}$ Increased Vulnerability with Complete Symmetry

In Figure 3 we explore the effects of increased vulnerability under conditions of complete symmetry by raising $Z$ to 2.0. Whereas defense is twice as effective as attack effort in Figure 2; now the reverse is true. All other parameters remain the same. Included in Figure 3 are numerical details, which we pass over here. A visual comparison of the Figures 2 and 3 reveals some minor changes in resource costs and appropriation levels. The more prominent and, it turns out, more general effect is the diminution of trade due to the widened price wedge. As each good becomes more vulnerable, its corresponding retention rate $r_{j}^{i}$ decreases in equilibrium. This in turn raises the import price of $\operatorname{good} X$ to player $A$ and lowers the export price of $X$ to $B$, for reasons explained previously. The widened price wedge decreases exchange and hence players' utilities, as suggested by the noticeably larger region of mutual gain left untapped at the final consumption point. 
To explore the effects of vulnerability further, we calculated additional solutions using the same parameters as in Figures 2 and 3 but with alternative vulnerability levels. The details are reported in Table 1. Three observations are in order. First, the relationship between vulnerability and the wedge effect is evident across the full range of vulnerabilities in the table. As vulnerability increases, the wedge between effective prices widens and trade flows diminish. Second, the relationships between vulnerability on the one hand and resource costs and appropriation levels on the other are nonmonotonic. When vulnerability increases from very low levels, fortification, attack, and appropriation initially increase as might be expected. However, as vulnerability continues to increase, the conflict variables eventually turn around and decrease as withdrawal of goods from trade diminishes appropriation opportunities. Third, if vulnerability increases sufficiently in the table, resource costs, appropriation, and exchange all converge to zero. The final outcome is the same as autarky, with the price wedge forming at the initial endowment point and leaving untapped the entire initial region of mutual gain. We return to this case of autarky by convergence in Section 4 below.

Increased Vulnerability of One Good Only

We turn now to the question of what happens when vulnerability increases for one good only. With Figure 2 serving again as the base case, in Figure 4 we increase the vulnerability of $Y$ from 0.5 to 2.0 , while holding the vulnerability of $X$ constant at 0.5 . Among the contrasts evident between Figures 2 and 4, the more important one is again the diminution of trade due to a larger price wedge. Notice in Figure 4, however, that the wedge is skewed against player $A$ around a world price below 1.0. All else equal, an increase in $Z^{Y}$ reduces the retention rate $r_{A}^{Y}$ and hence raises player $A$ 's effective import price $P_{A}=P / r_{A}^{Y}$. This in turn decreases demand for $X$ and lowers the equilibrium world price. Predictably, the increased vulnerability of $Y$ works against 
the interests of player $A$, who holds a comparative advantage in the more vulnerable good. Player $A$ suffers not only reduced trade due to the wedge effect but also increased piracy from player $B .^{7}$

In Table 2 we place the examples of Figures 2 and 4 in the context of a series of solutions for increasing levels of vulnerability of good $Y$. With details left to the table, we highlight several principles. When vulnerability of $Y$ increases, the world price falls, the price wedge widens, and trade diminishes. Decreased trade in $X$ reduces appropriation opportunities, so that equilibrium defense, attack, and appropriation of good $X$ likewise diminish. In contrast, the same variables for good $Y$ first rise as increasing vulnerability shifts incentives toward conflict. Eventually, the widening price wedge turns these variables downward, reinforced by some economizing of attack resources made possible by their greater effectiveness. Player B's utility is bolstered by piracy but depressed by resource cost and wedge effects. With the comparative advantage in $Y$, Player $A$ loses on all counts. A's utility falls steadily until $A$ is rendered indifferent between trade and autarky at a vulnerability level $Z^{Y}=28.5$.

We illustrate this case of autarky by indifference with $Z^{Y}=28.5$ in Figure 5, which shows the price wedge further widened and skewed against player $A$. After allowing for resource costs and appropriation, trade places the players at point $d$, lying precisely on A's indifference curve passing through the initial endowment point $a$. Any further increase in vulnerability causes player $A$ to forgo trade, shifting the economy to autarky. We pursue questions pertaining to vulnerable trade and autarky more closely in the next section.

\section{VULNERABLE TRADE AND AUTARKY}

We employ again the assumption of complete symmetry to explore two related questions: What determines the level of vulnerability that cuts off trade, and what characterizes the 
emergence of autarky as an equilibrium? We begin with tentative answers to the two questions and then follow with evidence from numerical solutions.

The level of vulnerability at which trade is extinguished depends on the mutual gains that would be available if trade were secure. The greater the potential gains in the classic Edgeworth box economy, the more robust is trade with respect to increases in vulnerability. The potential gains in turn depend on the initial endowment point and the curvature of the indifference curves. The farther the endowment point from the contract curve and the more convex the indifference curves, the greater is the vulnerability level that cuts off trade.

Turning to the second question, increased vulnerability can generate autarky in two distinct ways, as discovered in the preceding section. The trade equilibrium can leave one or both players at a utility level equal to that under autarky, so that they are willing to forgo trade. Any gains to realized trade are offset by resource costs and appropriation losses. In terms of our Edgeworth box figures with complete symmetry, the final consumption point $d$ falls at the intersection of respective indifference curves corresponding to the initial-endowment utilities. This is autarky by indifference. Alternatively, the wedge effect can drive exports and likewise defense, attack, and appropriation to zero. In terms of the figures, the final consumption point $d$ converges to the initial endowment point $a$. This is autarky by convergence.

Seeking support for these answers, we ran a series of computations for alternative CES utility functions $(\sigma=1 / 2,1,2$, and 3$)$ under conditions of complete symmetry, but with endowments only partially fixed $\left(E_{A}^{X}=E_{B}^{Y}=100\right)$. For values of $Z$ from 0 to 5.0 , we computed corresponding endowment values $\left(E_{A}^{Y}=E_{B}^{X}\right)$ for which players' utilities at the trade equilibrium just equaled their utilities under autarky. We present the results in Figure 6. For each elasticity of substitution, we plot a locus of points above which combinations of vulnerability and relative 
endowment disparity generate trade and below which they yield autarky. ${ }^{8}$ To anticipate, the results confirm the answers above, but they also hold several surprises.

Figure 6 shows that the level of vulnerability at which trade is extinguished is systematically related to relative endowment disparity and elasticity of substitution. Holding relative endowments fixed, the smaller the elasticity of substitution, and hence the more convex the indifference curves, the larger is the critical level of vulnerability. As a result, trade is more robust to vulnerability when substitutability between goods is low. For example, at point $m$ for which vulnerability is $Z=1.0$ and $A$ 's relative endowment is $E_{A}^{Y} / E_{A}^{X}=600 / 100=6$, trade will fail to emerge if $\sigma=3$ but arise if $\sigma=2$. It is also true that holding substitutability constant, the larger is the relative endowment disparity, then the greater is the minimum vulnerability at which trade is extinguished. Accordingly, trade is more robust when the difference in relative endowments is larger. For example, suppose $Z=1.0$ and $\sigma=3$. Then trade will not exist when $A$ 's relative endowment is $E_{A}^{Y} / E_{A}^{X}=600 / 100=6$ at point $m$ but will arise when it is $1000 / 100=10$ at point $p$.

As mentioned above, Figure 6 presents some surprises, foremost of which is the nonmonotonic pattern of the trade-autarky loci. The implication is that holding endowment disparity and substitutability constant, increases in vulnerability can shift an economy from trade to autarky, back to trade, and then again to autarky. For example, consider in Figure 6 the dashed horizontal line plotted for increasing levels of vulnerability, holding endowment disparity and substitutability fixed at $E_{A}^{Y} / E_{A}^{X}=825 / 100=8.25$ and $\sigma=3$. As vulnerability increases, trade reigns until indifference point $u$, is taken over by autarky until indifference point $v$, emerges again up to convergence point $w$, and is extinguished for all points beyond. The numerical details for these shifts between trade and autarky are presented in Table 3 . 
The movements between trade and autarky can be understood in terms of the principles discovered in the preceding sections. Recall that trade vulnerability generates both a resource cost effect and a wedge effect on players' utilities. The first effect refers to the diversion of resources for defense and attack, while the second refers to the spread between effective export and import prices due to piracy. Also recall that the resource cost effect is nonmonotonic. Resource costs first increase with vulnerability but then diminish as defense and attack levels converge to zero. The wedge effect, on the other hand, increases relentlessly. Together this means that as vulnerability increases beyond comparatively low levels, a tradeoff arises between trade promotion due to reduced allocations to defense and attack and trade hindrance due to a widened price wedge.

Now apply these principles to the increases in vulnerability along the dashed line of Figure 6. As the economy approaches point $u$, the resource cost effect diminishes, thus increasing the amount of goods available for gross exports. The increasing wedge effect dominates, however, reducing the potential gains available from gross exports. At point $u$ players become indifferent to trade, and with further increases in vulnerability they opt out of trade. None of this is too remarkable. The surprise comes in the movement from point $u$ to a second indifference point $v$. Somewhere along this path the resource cost effect diminishes at a rate sufficient to offset the increasing wedge effect. Prospective utilities increase until players become indifferent to trade at point $v$ and then opt back into trade with further movement to the right. Eventually the resource cost effect diminishes at a diminishing rate, as defense and attack levels are reduced toward zero. The still increasing wedge effect reasserts its dominance until trade converges to autarky at point w. Beyond this point, A's effective price of $X$ becomes too high and $B$ 's too low to permit advantageous trade, and autarky rules. 


\section{CONCLUSION}

Only in recent decades has appropriation begun to be treated as a basic form of economic activity. Perhaps the artificial separation of exchange and appropriation traces back to Adam Smith. As Smith (1976 [1776], 17) so famously observed, "the propensity to truck, barter, and exchange ... is common to all men, and to be found in no other race of animals .... Nobody ever saw a dog make a fair and deliberate exchange ... with another dog." Following Smith, the economics discipline has emphasized something that distinguishes humans from other animals: mutually beneficial exchange. Generally ignored has been what makes humans similar to animals: the propensity to appropriate and defend. Standard models of exchange assume that people and property are perfectly secure, thus ignoring the contrary conditions pervasive in all economies to greater or lesser degrees. When people and property are insecure, opportunities exist to forcibly seize wealth. Scarce resources are allocated to appropriation and defense, wealth is redistributed, and consumption and trade are reduced.

In our model of vulnerable trade we assume that goods are subject to appropriation if and only if they are offered for trade. Initial endowments and the technology of conflict are exogenous; all other variables are determined endogenously. As expected in a general equilibrium model, the introduction of appropriation opportunities changes everything relative to the classic Edgeworth box economy, sometimes in unanticipated ways. Assuming nonprohibitive levels of vulnerability, appropriation possibilities create incentives to allocate resources to the seizure and defense of goods offered for trade. This resource cost causes the Edgeworth box to shrink, implying a reduction in goods available for consumption. In the reduced box an equilibrium emerges that includes both coerced redistribution and voluntary trade. Resource allocations together with the technology of conflict determine each good's 
piracy rate, measured as the percentage of gross exports appropriated. Goods not seized are realized exports and trade at the Walrasian relative price. At the final equilibrium, potential mutual gains remain untaken because the prospect of piracy creates a price wedge, lowering the effective relative price for the exporting player and raising it for the importing player. In cases of asymmetric vulnerability, the price wedge is skewed against the interests of the exporter of the more vulnerable good.

As the vulnerability of one or both goods increases, the price wedge widens, causing trade to diminish. The effects on resource costs and appropriation levels are nonmonotonic, however. While investments in conflict initially increase, the reduction in goods offered for trade decreases appropriation opportunities. This in turn eventually causes resource costs and appropriation levels to diminish. If vulnerability becomes sufficiently high, then trade and appropriation are driven to zero, or one or both players are rendered indifferent to trade. In either way, autarky arises as the equilibrium outcome. Whereas traditional economics assumes that exchange generates gains relative to autarky, with appropriation possibilities autarky can be preferred to exchange. Even when exchange emerges over autarky, appropriation possibilities complicate exchange in ways that are generally ignored in economic theory. 


\section{REFERENCES}

Anderson, J.E., and D. Marcouiller. "Anarchy and Autarky: Endogenous Predation as a Barrier to Trade." Boston College Department of Economics Working Paper, 2001.

Anderton, C.H. "Appropriation Possibilities in a Simple Exchange Economy." Economics Letters, 63(1), 1999, 77-83.

Anderton, C.H. "Conflict and Trade in a Predator/Prey Economy." Review of Development Economics, 7(1), 2003, 15-29.

Anderton, C.H. and R.A. Anderton. "The Economics of Conflict, Production and Exchange," in Economics of Conflict and Peace, edited by J. Brauer and W. Gissy. Aldershot, UK: Avebury Press, 1997, 54-82.

Anderton, C.H., R.A. Anderton, J.R. Carter. "Economic Activity in the Shadow of Conflict." Economic Inquiry, 37(1), 1999, 166-79.

Brito, D.L. and M.D. Intriligator. "Conflict, War and Redistribution." American Political Science Review, 79(4), 1985, 943-57.

Carter, J.R., and C.A. Anderton. "An Experimental Test of a Predator-Prey Model of Appropriation." Journal of Economic Behavior \& Organization, 45(1), 2001, 83-97.

Collier, P., L. Elliott, H. Hegre, A. Hoeffler, M. Reynal-Querol, and N. Sambanis. -Breaking the Conflict Trap: Civil War and Development Policy. Washington, DC: The World Bank and Oxford University Press, 2003.

Durham, Y., J. Hirshleifer, and V.L. Smith. "Do the Rich Get Richer and the Poor Poorer? Experimental Tests of a Model of Power." American Economic Review, 88(4), 1998, 97083. 
Garfinkel, M.R. and S. Skaperdas. "Contract or War? On the Consequences of a Broader View of Self-Interest in Economics." American Economist, 44(Spring), 2000, 5-16.

Gosse, P. The History of Piracy. New York: Burt Franklin, [1932] 1968.

Grossman, H.I. and M. Kim, "Swords or Plowshares? A Theory of the Security of Claims to Property." Journal of Political Economy, 103(6), 1995, 1275-88.

Hausken, K. "Mutual Raiding of Production and the Emergence of Exchange." Paper presented at Analyzing Conflict: Insights from the Natural and Social Sciences Conference, UCLA, April 24-26, 2003.

Hirshleifer, J. "Conflict and Rent-Seeking Success Functions: Ratio vs. Difference Models of Relative Success." Public Choice, 63(2), 1989, 101-12.

Hirshleifer, J. "The Dark Side of the Force." Economic Inquiry, 32(1), 1994, 1-10.

Hirshleifer, J. "Anarchy and its Breakdown." Journal of Political Economy, 103(1), 1995, 2652.

Hirshleifer, J. "The Macrotechnology of Conflict." Journal of Conflict Resolution, 44(6), 2000, $773-92$.

Mas-Colell, A., M.D. Whinston, and J.P. Green. Microeconomic Theory. New York: Oxford University Press, 1995.

Neary, H.M. "Equilibrium Structure in an Economic Model of Conflict." Economic Inquiry, 35(3), 1997, 480-94.

Rider, R. "Plunder or Trade?" Defence and Peace Economics, 13(3), 2002, 199-214.

Skaperdas, S. "Cooperation, Conflict, and Power in the Absence of Property Rights." American Economic Review, 82(4), 1992, 720-39.

Skaperdas, S. "Contest Success Functions." Economic Theory, 7(2), 1996, 283-90. 
Skaperdas, S. and C. Syropoulos. "Insecure Property and the Efficiency of Exchange." The Economic Journal, 112(476), 2002, 133-146.

Smith, A. The Wealth of Nations. Chicago: University of Chicago Press, [1776] 1976.

Usher, D. "The Dynastic Cycle and the Stationary State." American Economic Review, 79(5), $1989,1031-44$. 


\section{NOTES}

* An earlier version of this paper was presented at the Allied Social Science Association Meetings in Atlanta, January 6, 2002. We wish to thank Jurgen Brauer and Todd Sandler for their helpful comments.

Charles H. Anderton: Professor, College of the Holy Cross, Worcester, MA 01610. Phone 1508-793-3441, FAX 1-508-793-3708, E-mail canderto@holycross.edu.

John R. Carter: Professor, College of the Holy Cross, Worcester, MA 01610. Phone 1-508-7932676, FAX 1-508-793-3708, E-mail jcarter@holycross.edu.

1. For models of production and appropriation, see Brito and Intriligator (1985), Garfinkel and Skaperdas (2000), Grossman and Kim (1995), Hirshleifer (1995), Neary (1997), Skaperdas (1992), and Usher (1989). Models of exchange and appropriation include Anderton and Anderton (1997), Anderton (1999), and Skaperdas and Syropoulos (2002). For models that combine production, exchange, and appropriation see Anderson and Marcoullier (2001), Anderton et al. (1999), Anderton (2003), Hausken (2003), and Rider (2002). Experimental tests of models with production and appropriation include Durham et al. (1998) and Carter and Anderton (2001).

2. To our knowledge, Anderson and Marcoullier (2001) offer the only other general equilibrium model of trade and appropriation where autarky arises as an equilibrium outcome under certain conditions.

3. Once appropriated, goods are not traded; once traded, they are not appropriated.

4. On contest success functions, see Hirshleifer $(1989,2000)$ and Skaperdas (1996). Our particular contest success function is identical to that of Grossman and Kim (1995). 
5. Numerical solutions were computed with Maple 8.00 and are available from the authors upon request. In cases of complete symmetry, selected computations were checked against the analytical solution in the Appendix.

6. An interesting feature discovered in this and subsequent numerical examples is that one player's optimal fortification equals the other player's appropriation of the same good. For A's fortification of good Y, the result is easily proven from A's first-order condition (7) together with the ratio-form contest success function (10). After substituting $\partial r_{A}^{Y} / \partial h_{A}^{\curlyvee}$ from (10) and simplifying, (7) can be written as $h_{A}^{Y}=\left(E_{A}^{Y}-h_{A}^{Y}-Y_{A}\right)\left(Z^{Y} g_{B}^{Y} /\left(h_{A}^{Y}+Z^{Y} g_{B}^{Y}\right)\right)$, where the right-hand side equals B's appropriation of good Y. A similar proof holds for B's fortification of X.

7. Our model of vulnerable trade easily accommodates the special case of player A as prey and player B as predator. Because both Player A's attack and player B's fortification equal zero, player B's retention ratio equals one by definition. Player B's effective price thus equals the world price, and the wedge is formed between that price and A's effective price.

8. A locus of $\left(Z, E_{A}^{Y}\right)$ points showing autarky by convergence is derived by setting the numerator of equation (A.1) in the Appendix to zero. The resulting $\left(Z, E_{A}^{Y}\right)$ points give $h=0$, $g=0, Y_{A}=E_{A}{ }^{Y}$, and $X_{A}=E_{A}{ }^{X}$ in equations (A.1)-(A.4), confirming autarky by convergence. The denominator in (A.1) can be shown to be positive, which implies that $\partial \mathrm{h} / \partial E_{A}{ }^{Y}$ is positive and independent of $E_{A}{ }^{Y}$. Hence, autarky exists for all $\left(Z, E_{A}^{Y}\right)$ points on and below the autarky-byconvergence locus. Points above the autarky-by-convergence locus do not necessarily imply trade because trade can leave players worse off than under autarky. For $\left(Z, E_{A}^{Y}\right)$ points above the autarky-by-convergence locus, our computations reveal trade for $Z \geq 2$. For $Z<2,\left(Z, E_{A}^{Y}\right)$ 
points directly above the autarky-by-convergence locus show autarky dominating trade until the concave autarky-by-indifference locus is reached, above which trade reigns. 
TABLE 1

Increasing Vulnerability with Complete Symmetry ${ }^{\mathrm{a}}$

\begin{tabular}{|c|c|c|c|c|c|c|c|c|c|c|c|}
\hline$Z$ & $X_{A}=Y_{B}$ & $Y_{A}=X_{B}$ & $h$ & $g$ & $P$ & Approp & $\begin{array}{l}\text { Realized } \\
\text { Exports }\end{array}$ & $r$ & $P_{A}$ & $P_{B}$ & $U$ \\
\hline 0.0 & 450.0 & 450.0 & 0.0 & 0.0 & 1.00 & 0.0 & 350.0 & 1.00 & 1.00 & 1.00 & 450.0 \\
\hline 0.1 & 404.9 & 442.0 & 27.7 & 25.4 & 1.00 & 27.7 & 302.6 & 0.92 & 1.09 & 0.92 & 423.0 \\
\hline 0.2 & 375.4 & 439.5 & 45.9 & 39.2 & 1.00 & 45.9 & 268.7 & 0.85 & 1.17 & 0.85 & 406.2 \\
\hline 0.3 & 354.2 & 439.8 & 58.7 & 47.3 & 1.00 & 58.7 & 242.8 & 0.81 & 1.24 & 0.81 & 394.7 \\
\hline 0.4 & 338.2 & 441.7 & 68.0 & 52.1 & 1.00 & 68.0 & 222.2 & 0.77 & 1.31 & 0.77 & 386.5 \\
\hline 0.5 & 325.4 & 444.5 & 75.1 & 55.0 & 1.00 & 75.1 & 205.3 & 0.73 & 1.37 & 0.73 & 380.3 \\
\hline 0.6 & 314.9 & 447.8 & 80.6 & 56.7 & 1.00 & 80.6 & 191.0 & 0.70 & 1.42 & 0.70 & 375.5 \\
\hline 0.7 & 306.1 & 451.4 & 84.9 & 57.6 & 1.00 & 84.9 & 178.8 & 0.68 & 1.47 & 0.68 & 371.8 \\
\hline 0.8 & 298.6 & 455.3 & 88.3 & 57.9 & 1.00 & 88.3 & 168.2 & 0.66 & 1.52 & 0.66 & 368.7 \\
\hline 0.9 & 292.0 & 459.2 & 91.0 & 57.8 & 1.00 & 91.0 & 158.9 & 0.64 & 1.57 & 0.64 & 366.2 \\
\hline 1.0 & 286.2 & 463.1 & 93.1 & 57.5 & 1.00 & 93.1 & 150.7 & 0.62 & 1.62 & 0.62 & 364.1 \\
\hline 2.0 & 250.0 & 500.0 & 100.0 & 50.0 & 1.00 & 100.0 & 100.0 & 0.50 & 2.00 & 0.50 & 353.6 \\
\hline 3.0 & 230.1 & 529.9 & 97.6 & 42.4 & 1.00 & 97.6 & 74.9 & 0.43 & 2.30 & 0.43 & 349.2 \\
\hline 4.0 & 216.4 & 554.2 & 93.1 & 36.3 & 1.00 & 93.1 & 59.6 & 0.39 & 2.56 & 0.39 & 346.3 \\
\hline 5.0 & 205.8 & 574.4 & 88.2 & 31.6 & 1.00 & 88.2 & 49.2 & 0.36 & 2.79 & 0.36 & 343.8 \\
\hline 10.0 & 173.4 & 641.8 & 66.7 & 18.0 & 1.00 & 66.7 & 24.7 & 0.27 & 3.70 & 0.27 & 333.6 \\
\hline 20.0 & 142.0 & 710.0 & 40.0 & 8.0 & 1.00 & 40.0 & 10.0 & 0.20 & 5.00 & 0.20 & 317.5 \\
\hline 30.0 & 124.6 & 747.6 & 23.8 & 4.0 & 1.00 & 23.8 & 4.8 & 0.17 & 6.00 & 0.17 & 305.2 \\
\hline 40.0 & 112.9 & 772.7 & 12.6 & 1.8 & 1.00 & 12.6 & 2.2 & 0.15 & 6.84 & 0.15 & 295.4 \\
\hline 50.0 & 104.2 & 791.1 & 4.2 & 0.5 & 1.00 & 4.2 & 0.6 & 0.13 & 7.59 & 0.13 & 287.2 \\
\hline 56.0 & 100.0 & 800.0 & 0.0 & 0.0 & 1.00 & 0.0 & 0.0 & 0.12 & 8.03 & 0.12 & 282.8 \\
\hline
\end{tabular}

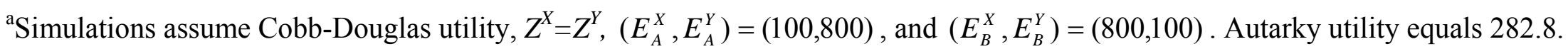


TABLE 2

Increasing Vulnerability for One Good Only ${ }^{\mathrm{a}}$

\begin{tabular}{|c|c|c|c|c|c|c|c|c|c|c|c|c|c|c|c|c|c|c|c|}
\hline$Z^{Y}$ & $X_{A}$ & $Y_{A}$ & $h_{A}{ }^{Y}$ & $g_{A}{ }^{X}$ & $X_{B}$ & $Y_{B}$ & $h_{B}{ }^{X}$ & $g_{B}{ }^{Y}$ & $P$ & $\operatorname{App}_{A}{ }^{X}$ & $A p p_{B}{ }^{Y}$ & $\begin{array}{c}\text { Realized } \\
\operatorname{Exp}_{A}{ }^{Y} \\
\end{array}$ & $\begin{array}{c}\text { Realized } \\
\operatorname{Exp}_{B}{ }^{X} \\
\end{array}$ & $r_{A}^{Y}$ & $P_{A}$ & $r_{B}^{X}$ & $P_{B}$ & $U_{A}$ & $U_{B}$ \\
\hline 0.5 & 325.4 & 444.5 & 75.1 & 55.0 & 444.5 & 325.4 & 75.1 & 55.0 & 1.00 & 75.1 & 75.1 & 205.3 & 205.3 & 0.73 & 1.37 & 0.73 & 0.73 & 380.3 & 380.3 \\
\hline 0.6 & 321.2 & 441.2 & 82.1 & 54.0 & 451.1 & 319.0 & 73.7 & 57.7 & 0.97 & 73.7 & 82.1 & 194.6 & 201.5 & 0.70 & 1.37 & 0.73 & 0.71 & 76.5 & 379.3 \\
\hline 0.7 & 317.3 & 438.5 & 88.0 & 53.0 & 457.3 & 313.8 & 72.4 & 59.7 & 0.94 & 72.4 & 88.0 & 185.4 & 197.9 & 0.68 & 1.38 & 0.73 & 0.69 & 373.0 & 378.8 \\
\hline 0.8 & 313.5 & 436.3 & 93.1 & 52.1 & 463.2 & 309.5 & 71.2 & 61.1 & 0.91 & 71.2 & 93.1 & 177.5 & 194.4 & 0.66 & 1.39 & 0.73 & 0.67 & 369.8 & 378.7 \\
\hline 0.9 & 309.9 & 434.4 & 97.6 & 51.2 & 468.8 & 306.0 & 70.0 & 62.0 & 0.89 & 70.0 & 97.6 & 170.4 & 191.2 & 0.64 & 1.40 & 0.73 & 0.65 & 367.0 & 378.7 \\
\hline 1.0 & 306.6 & 432.9 & 101.5 & 50.4 & 474.2 & 302.9 & 68.9 & 62.7 & 0.87 & 68.9 & 101.5 & 164.2 & 188.1 & 0.62 & 1.41 & 0.73 & 0.64 & 364.3 & 379.0 \\
\hline 2.0 & 280.1 & 425.9 & 124.7 & 44.0 & 515.9 & 287.1 & 60.0 & 62.4 & 0.76 & 60.0 & 124.7 & 7 & .1 & 0.50 & 1.52 & 0.73 & 0.56 & 345.4 & 384.8 \\
\hline 3.0 & 262.1 & 425.1 & 135.5 & 39.6 & 544.3 & 280.6 & 54.0 & 58.8 & 0.70 & 54.0 & 135.5 & 104.0 & 147.6 & 0.43 & 1.62 & 0.73 & 0.52 & 333.8 & 390.8 \\
\hline 4.0 & 248.7 & 426.3 & 141.5 & 36.3 & 565.4 & 276.9 & 49.6 & 55.3 & 0.67 & 49.6 & 141.5 & 90.6 & 135.5 & 0.39 & 1.71 & 0.73 & 0.49 & 325.6 & 395.7 \\
\hline 5.0 & 238.3 & 428.3 & 145.3 & 33.7 & 581.9 & 274.3 & 46.1 & 52.0 & 0.64 & 46.1 & 145.3 & 81.1 & 125.9 & 0.36 & 1.80 & 0.73 & 0.47 & 319.5 & 399.5 \\
\hline 10.0 & 206.8 & 441.2 & 151.4 & 26.0 & 631.6 & 266.5 & 35.6 & 40.9 & 0.58 & 35.6 & 101.4 & 56.0 & 97.2 & 0.27 & 2.13 & 0.73 & 0.42 & 302.0 & 410.3 \\
\hline 15.0 & 189.9 & 453.4 & 151.1 & 21.9 & 658.2 & 261.2 & 30.0 & 34.3 & 0.54 & 30.0 & 151.1 & 44.4 & 81.9 & 0.23 & 2.39 & 0.73 & 0.40 & 293.4 & 414.6 \\
\hline 20.0 & 178.9 & 464.3 & 149.2 & 19.3 & 675.5 & 256.7 & 26.3 & 29.8 & 0.52 & 26.3 & 149.2 & 37.3 & 71.9 & 0.20 & 2.59 & 0.73 & 0.38 & 288.2 & 416.4 \\
\hline 25.0 & 171.0 & 474.0 & 146.8 & 17.3 & 688.0 & 252.7 & 23.7 & 26.6 & 0.50 & 23.7 & 146.8 & 32.4 & 64.7 & 0.18 & 2.77 & 0.73 & 0.37 & 284.7 & 416.9 \\
\hline 28.5 & 166.6 & 480.2 & 145.0 & 16.3 & 694.9 & 250.1 & 22.2 & 24.7 & 0.49 & 22.2 & 145.0 & 29.8 & 60.7 & 0.17 & 2.88 & 0.73 & 0.36 & 282.8 & 416.9 \\
\hline
\end{tabular}

${ }^{\mathrm{a}}$ Simulations assume Cobb-Douglas utility, $Z^{X}=0.5,\left(E_{A}^{X}, E_{A}^{Y}\right)=(100,800)$, and $\left(E_{B}^{X}, E_{B}^{Y}\right)=(800,100)$. Autarky utility equals 282.8 . 
TABLE 3

Trade and Autarky with Increasing Vulnerability and Complete Symmetry ${ }^{\mathrm{a}}$

\begin{tabular}{|c|c|c|c|c|c|c|c|c|c|c|c|c|}
\hline$Z$ & $X_{A}=Y_{B}$ & $Y_{A}=X_{B}$ & $h$ & $g$ & $P$ & Approp & $\begin{array}{r}\text { Realized } \\
\text { Exports }\end{array}$ & $r$ & $P_{A}$ & $P_{B}$ & $U$ & Outcome \\
\hline 0.00 & 462.5 & 462.5 & 0.0 & 0.0 & 1.00 & 0.0 & 362.5 & 1.00 & 1.00 & 1.00 & 1308.15 & Trade \\
\hline 0.10 & 380.8 & 495.3 & 25.5 & 23.4 & 1.00 & 25.5 & 278.6 & 0.92 & 1.09 & 0.92 & 1235.44 & Trade \\
\hline 0.20 & 328.0 & 526.5 & 38.0 & 32.5 & 1.00 & 38.0 & 222.5 & 0.85 & 1.17 & 0.85 & 1197.49 & Trade \\
\hline 0.30 & 290.2 & 555.5 & 43.9 & 35.4 & 1.00 & 43.9 & 181.7 & 0.81 & 1.24 & 0.81 & 1175.98 & Trade \\
\hline 0.40 & 261.3 & 582.3 & 46.1 & 35.3 & 1.00 & 46.1 & 150.5 & 0.77 & 1.31 & 0.77 & 1163.25 & Trade \\
\hline 0.50 & 238.2 & 607.1 & 46.1 & 33.7 & 1.00 & 46.1 & 125.8 & 0.73 & 1.37 & 0.73 & 1155.54 & Trade \\
\hline 0.60 & 219.1 & 629.9 & 44.7 & 31.4 & 1.00 & 44.7 & 105.8 & 0.70 & 1.42 & 0.70 & 1150.87 & Trade \\
\hline 0.70 & 203.0 & 650.9 & 42.4 & 28.8 & 1.00 & 42.4 & 89.3 & 0.68 & 1.47 & 0.68 & 1148.06 & Trade \\
\hline 0.80 & 189.1 & 670.3 & 39.6 & 26.0 & 1.00 & 39.6 & 75.5 & 0.66 & 1.52 & 0.66 & 1146.44 & Trade \\
\hline 0.85 & 183.3 & 678.8 & 38.2 & 24.7 & 1.00 & 38.2 & 69.8 & 0.65 & 1.55 & 0.65 & 1145.96 & Indifference \\
\hline 0.90 & 177.0 & 688.3 & 36.5 & 23.2 & 1.00 & 36.5 & 63.8 & 0.64 & 1.57 & 0.64 & 1145.56 & Autarky \\
\hline 1.00 & 166.4 & 704.9 & 33.2 & 20.5 & 1.00 & 33.2 & 53.7 & 0.62 & 1.62 & 0.62 & 1145.15 & Autarky \\
\hline 1.20 & 148.4 & 734.6 & 26.4 & 15.5 & 1.00 & 26.4 & 37.5 & 0.59 & 1.70 & 0.59 & 1145.08 & Autarky \\
\hline 1.40 & 133.8 & 760.4 & 19.7 & 11.1 & 1.00 & 19.7 & 25.1 & 0.56 & 1.78 & 0.56 & 1145.39 & Autarky \\
\hline 1.60 & 121.6 & 782.9 & 13.3 & 7.2 & 1.00 & 13.3 & 15.5 & 0.54 & 1.86 & 0.54 & 1145.74 & Autarky \\
\hline 1.80 & 111.3 & 802.6 & 7.3 & 3.8 & 1.00 & 7.3 & 7.8 & 0.52 & 1.93 & 0.52 & 1145.95 & Autarky \\
\hline 1.81 & 110.9 & 803.4 & 7.0 & 3.6 & 1.00 & 7.0 & 7.5 & 0.52 & 1.93 & 0.52 & 1145.96 & Indifference \\
\hline 1.90 & 106.8 & 811.6 & 4.4 & 2.3 & 1.00 & 4.4 & 4.6 & 0.51 & 1.97 & 0.51 & 1145.99 & Trade \\
\hline 2.00 & 102.5 & 820.0 & 1.7 & 0.8 & 1.00 & 1.7 & 1.7 & 0.50 & 2.00 & 0.50 & 1145.98 & Trade \\
\hline 2.06 & 100.0 & 825.0 & 0.0 & 0.0 & 1.00 & 0.0 & 0.0 & 0.49 & 2.02 & 0.49 & 1145.96 & Autarky \\
\hline
\end{tabular}

${ }^{\mathrm{a}}$ Simulations assume $\operatorname{CES}(\sigma=3)$ utility, $Z^{X}=Z^{Y},\left(E_{A}^{X}, E_{A}^{Y}\right)=(100,825)$, and $\left(E_{B}^{X}, E_{B}^{Y}\right)=(825,100)$. Autarky utility equals 1145.96 . 
FIGURE 1. Illustration with Complete Symmetry

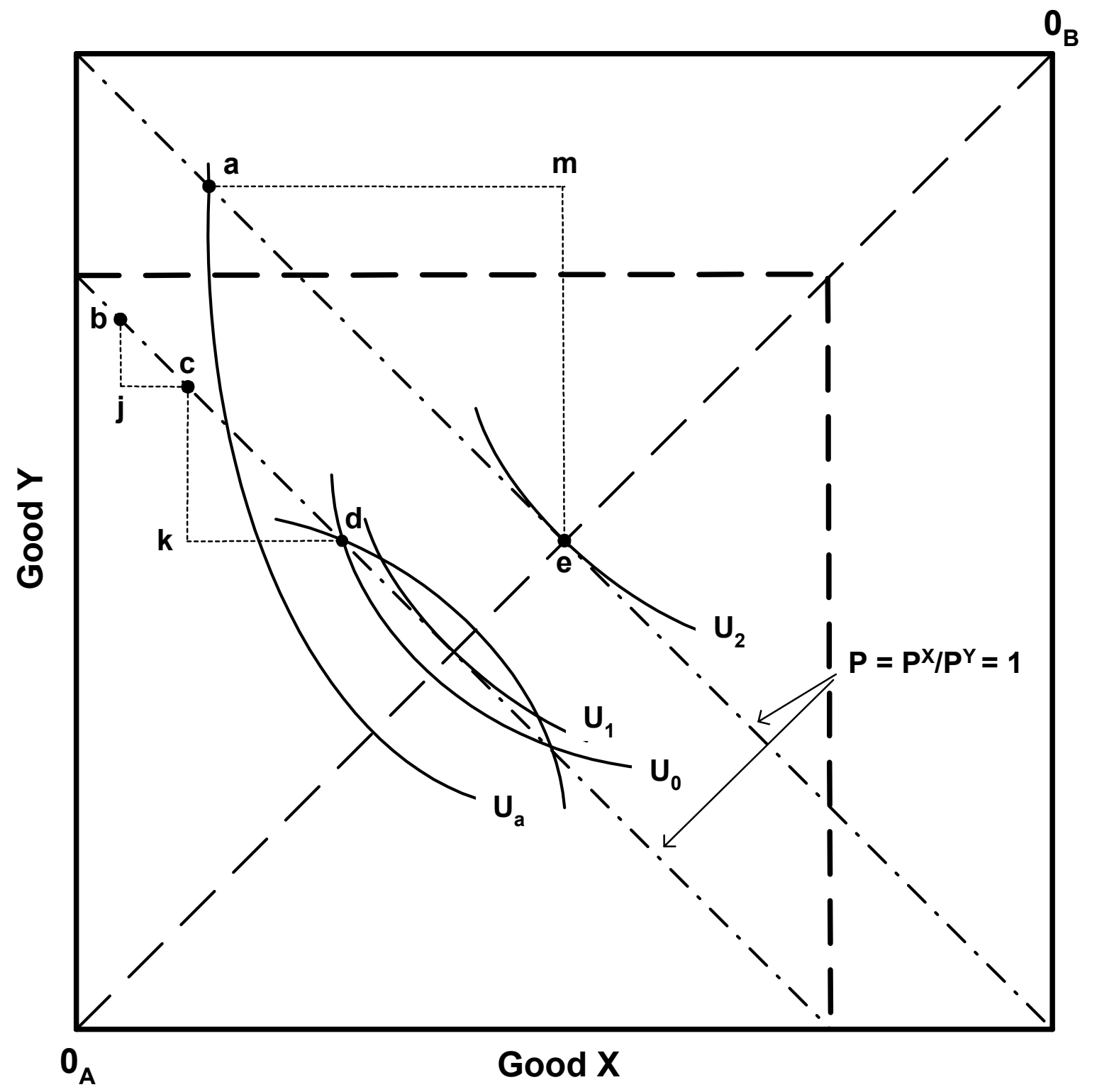


FIGURE 2. Base Example with $\left(Z^{X}, Z^{Y}\right)=(0.5,0.5)$
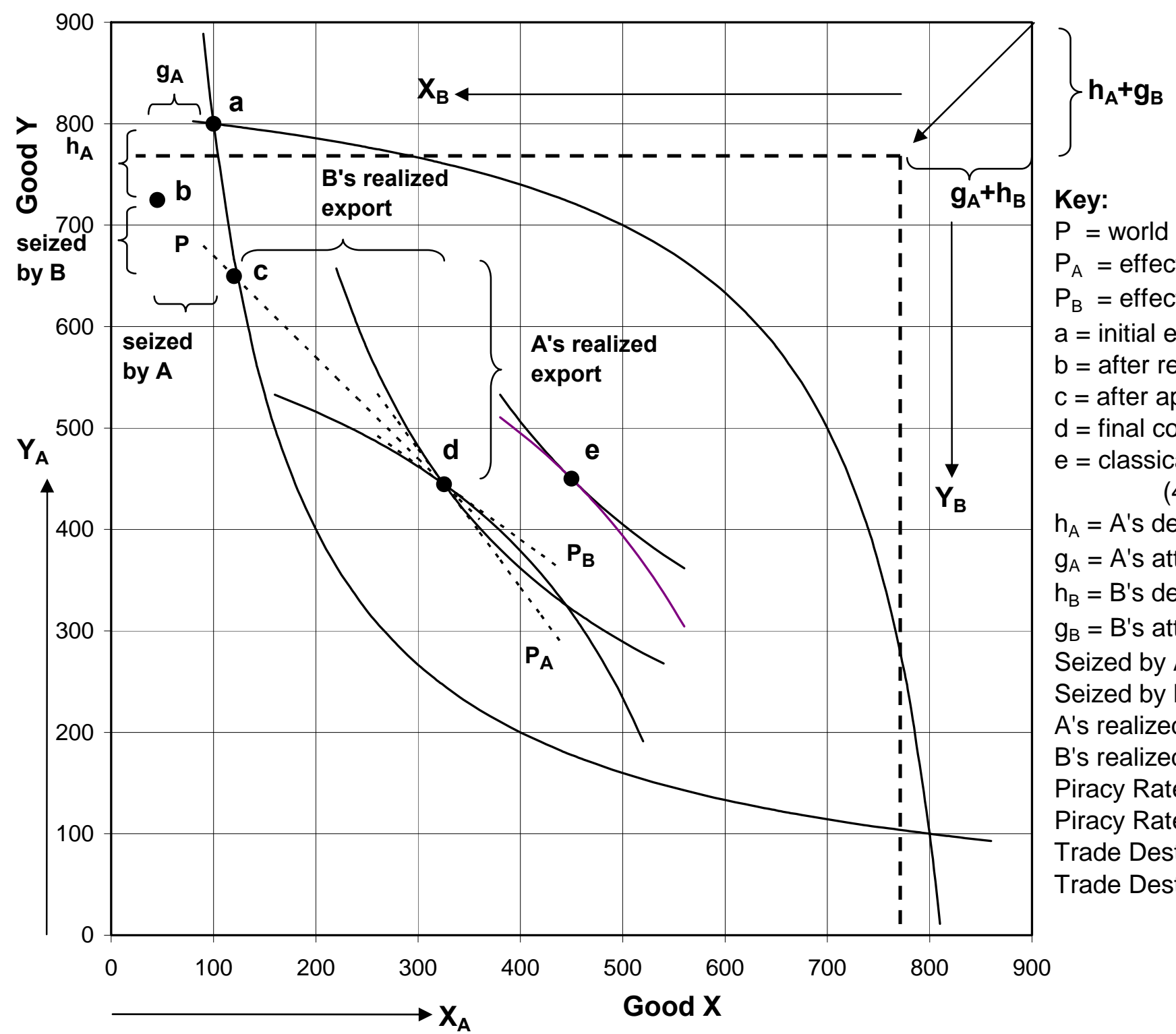

$P=$ world relative price of $X=1.000$

$P_{A}=$ effective price to $A=1.366$

$P_{B}=$ effective price to $B=0.732$

$a=$ initial endowment $=(100,800)$

$b=$ after resource cost $=(45.0,724.9)$

c $=$ after appropriation $=(120.1,649.8)$

$d=$ final consumption $=(325.4,444.5)$

$\mathrm{e}=$ classical consumption $=$

$$
(450.0,450.0)
$$

$\mathrm{h}_{\mathrm{A}}=\mathrm{A}^{\prime}$ 's defense $=75.1 \mathrm{Y}$

$g_{A}=A$ 's attack $=55.0 \mathrm{X}$

$\mathrm{h}_{\mathrm{B}}=\mathrm{B}$ 's defense $=75.1 \mathrm{X}$

$g_{B}=B^{\prime}$ s attack $=55.0 Y$

Seized by $A=75.1 X$

Seized by $B=75.1 Y$

A's realized export $=205.3 \mathrm{Y}$

B's realized export $=205.3 X$

Piracy Rate of $X=26.8 \%$

Piracy Rate of $Y=26.8 \%$

Trade Destruction Rate of $X=41.3 \%$

Trade Destruction Rate of $Y=41.3 \%$ 
FIGURE 3. Increased Vulnerability with $\left(Z^{X}, Z^{Y}\right)=(2.0,2.0)$
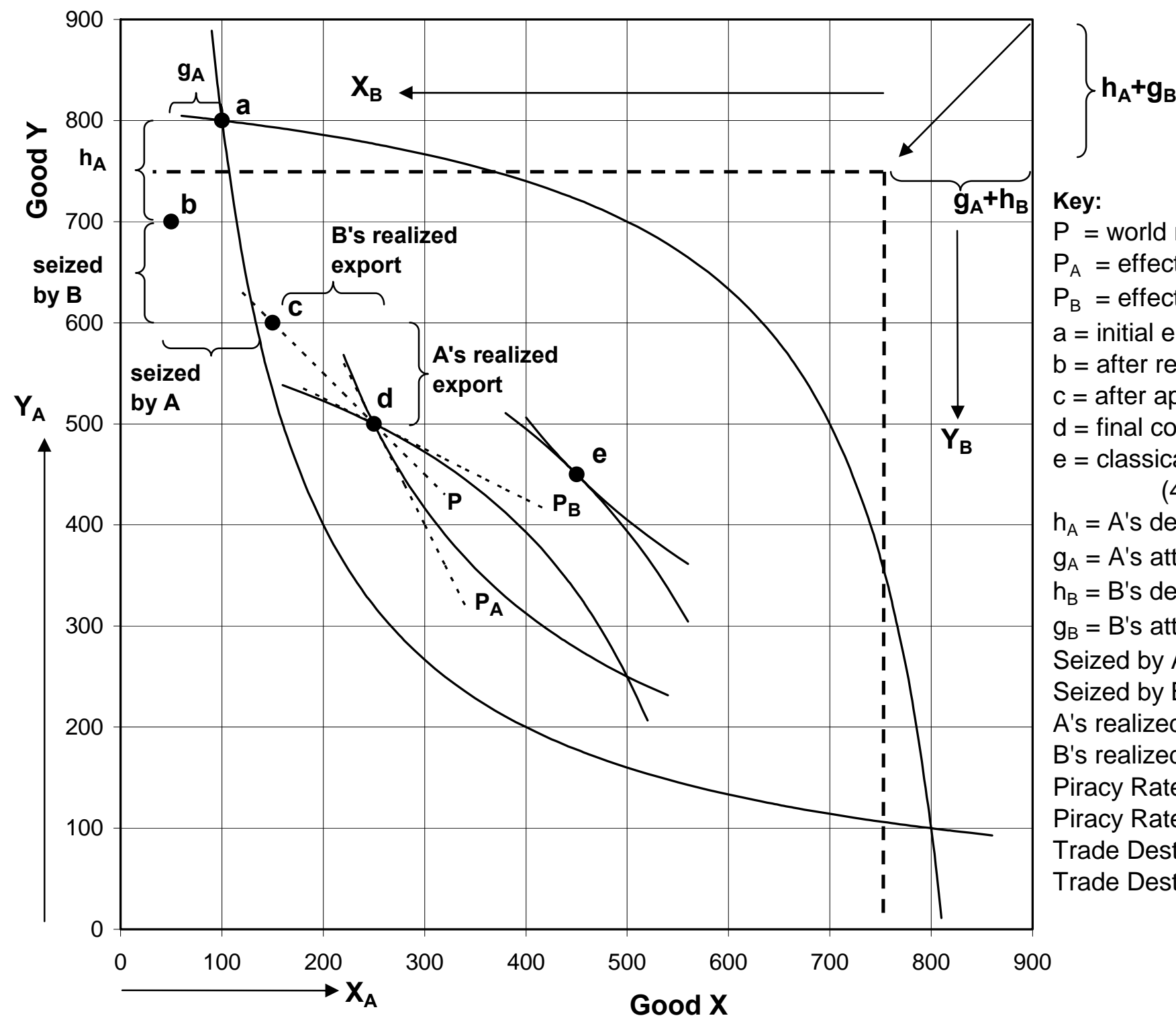

Key:

$\mathrm{P}=$ world relative price of $\mathrm{X}=1.000$

$\mathrm{P}_{\mathrm{A}}=$ effective price to $\mathrm{A}=2.000$

$\mathrm{P}_{\mathrm{B}}=$ effective price to $\mathrm{B}=0.500$

$a=$ initial endowment $=(100,800)$

$\mathrm{b}=$ after resource cost $=(50.0,700.0)$

$\mathrm{c}=$ after appropriation $=(150.0,600.0)$

$d=$ final consumption $=(250.0,500.0)$

$\mathrm{e}=$ classical consumption $=$ (450.0,450.0)

$\mathrm{h}_{\mathrm{A}}=\mathrm{A}$ 's defense $=100.0 \mathrm{Y}$

$\mathrm{g}_{\mathrm{A}}=\mathrm{A}^{\prime} \mathrm{s}$ attack $=50.0 \mathrm{X}$

$\mathrm{h}_{\mathrm{B}}=\mathrm{B}^{\prime}$ 's defense $=100.0 \mathrm{X}$

$g_{B}=B$ 's attack $=50.0 \mathrm{Y}$

Seized by $A=100.0 X$

Seized by $B=100.0 Y$

A's realized export $=100.0 \mathrm{Y}$

B's realized export $=100.0 X$

Piracy Rate of $X=50.0 \%$

Piracy Rate of $Y=50.0 \%$

Trade Destruction Rate of $X=71.4 \%$

Trade Destruction Rate of $Y=71.4 \%$ 
FIGURE 4. Increased Vulnerability with $\left(Z^{X}, Z^{Y}\right)=(0.5,2.0)$

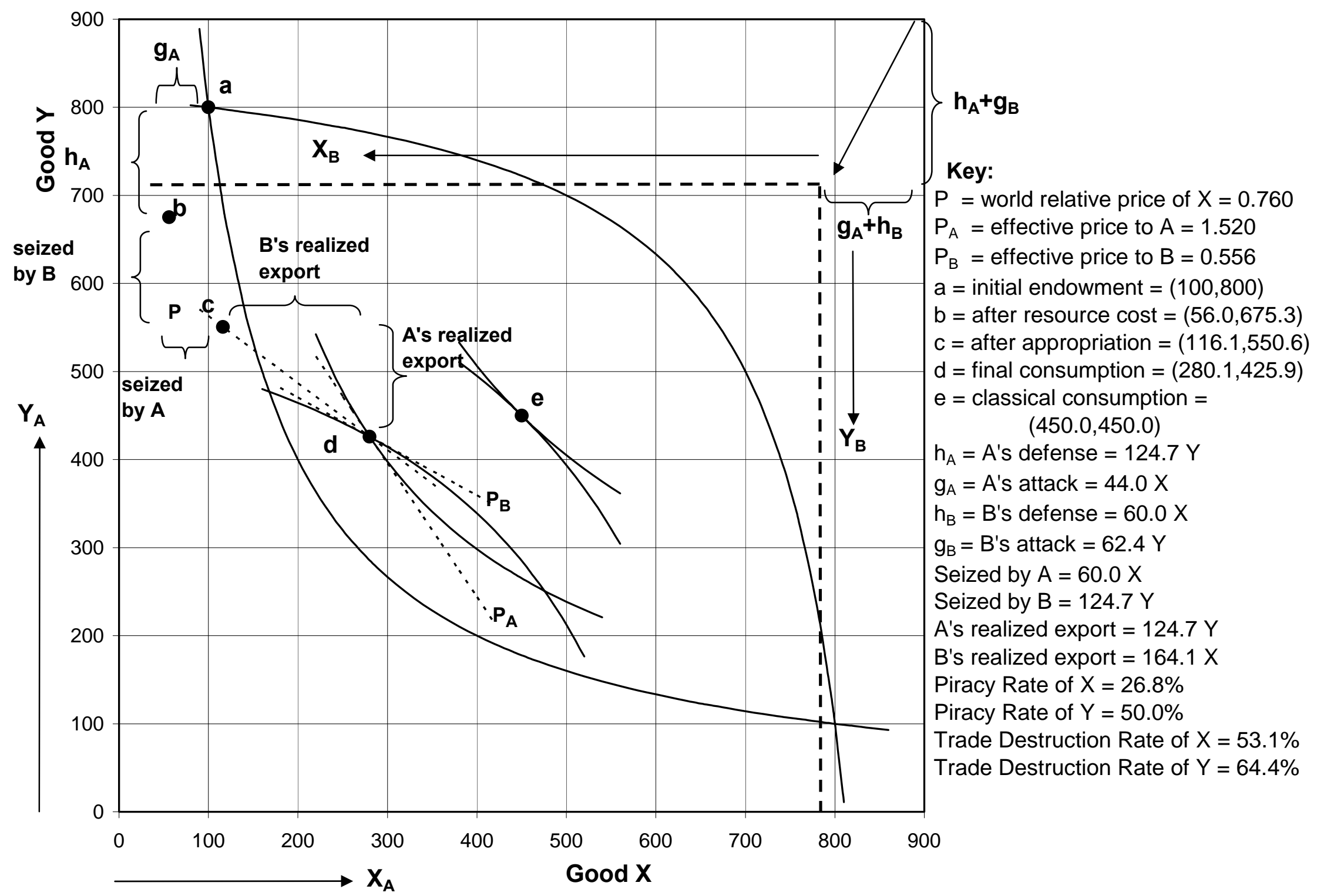


FIGURE 5. Increased Vulnerability with $\left(Z^{X}, Z^{Y}\right)=(0.5,28.5)$

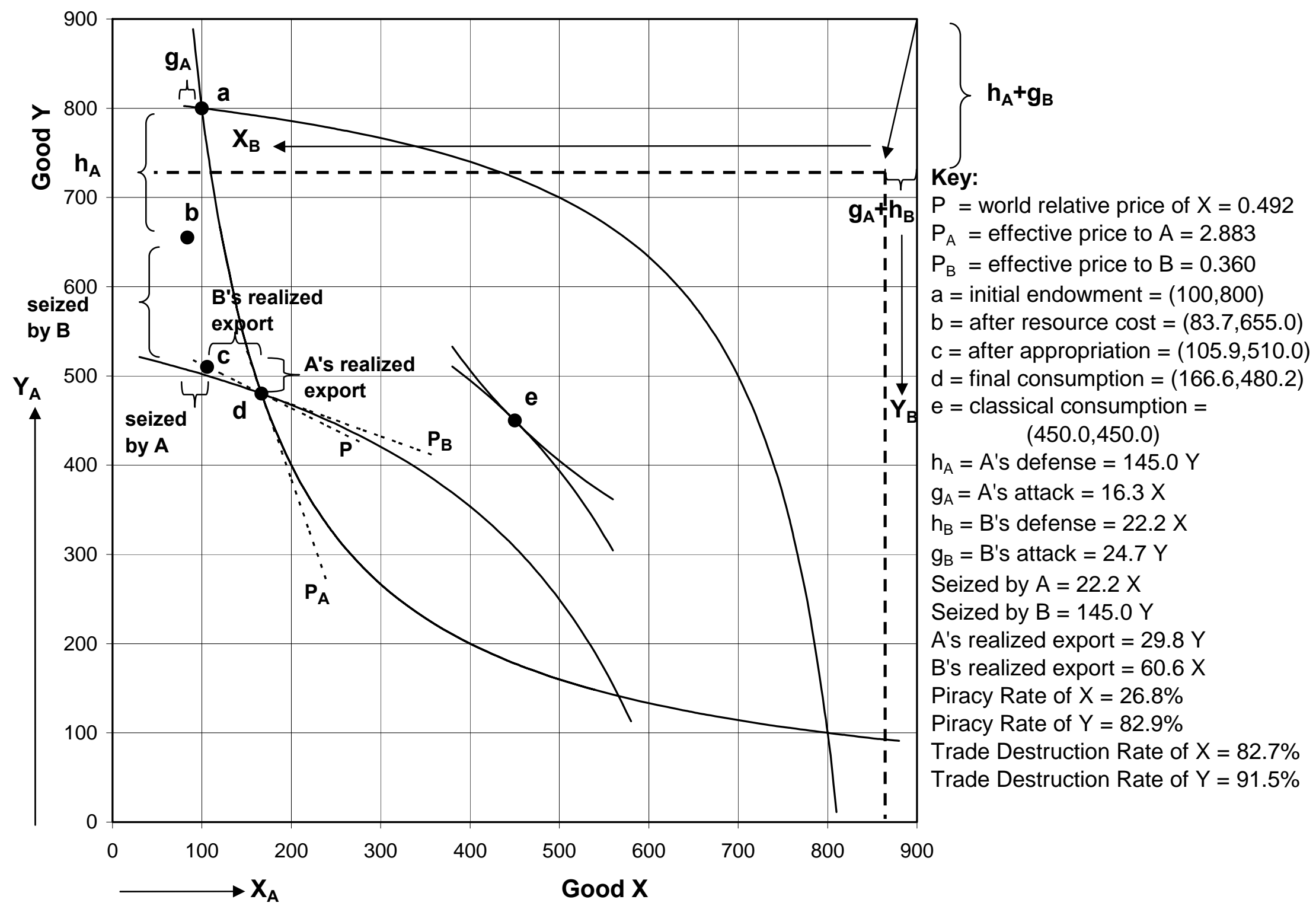


FIGURE 6. Autarky-Trade Loci

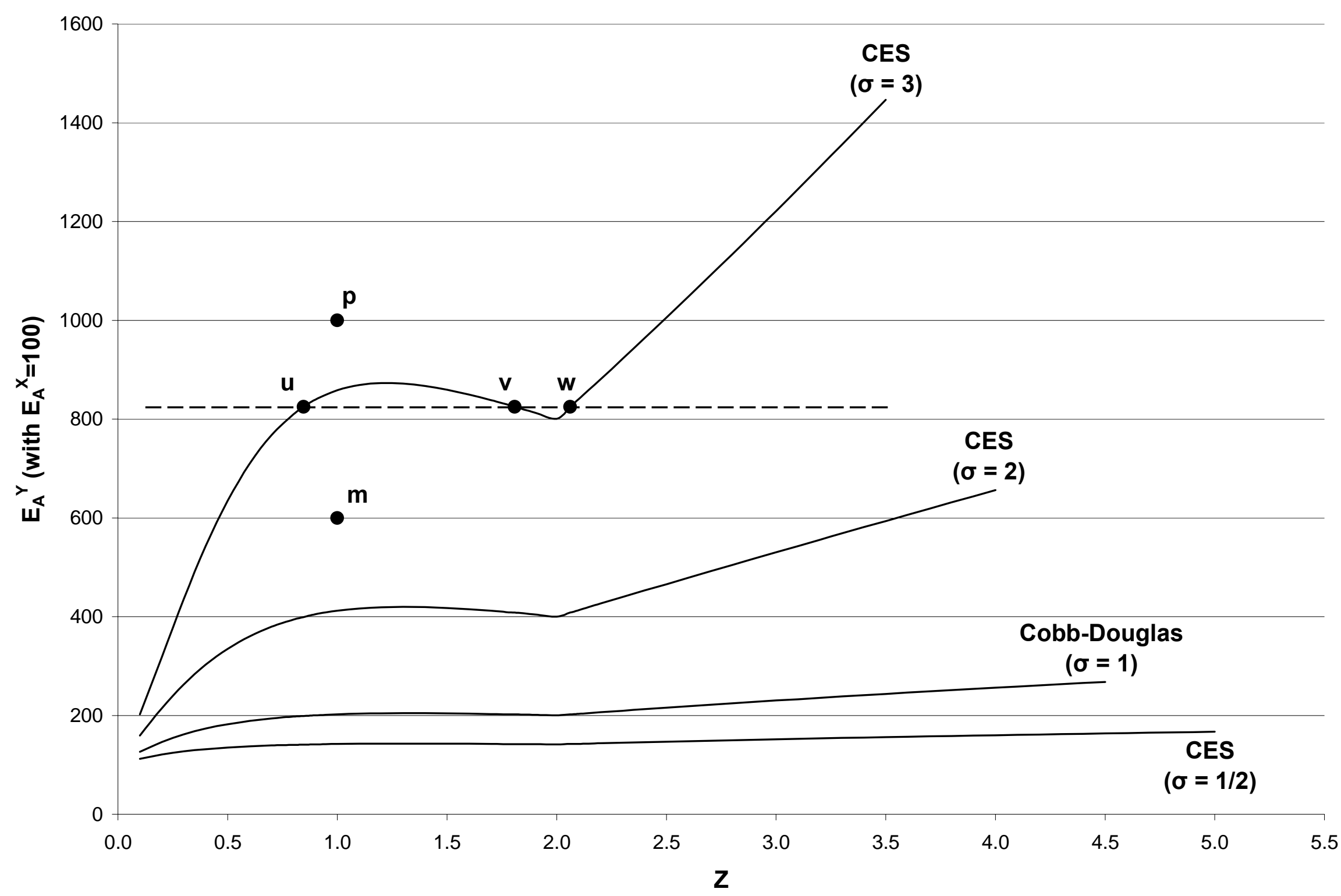




\section{APPENDIX}

Reduced-Form Solution with Complete Symmetry, CES Utility, and Ratio CSF

\section{$\underline{\text { Reduced-Form Solution }}$}

Assume complete symmetry (as defined in the paper), CES utility for each player $A$ and $B$, and identical ratio contest success functions for each good (as defined by equations 10 and 11). The reduced-form solution for player $A$ is:

$$
h_{A}=\frac{E_{A}^{Y}-E_{A}^{X}\left(\frac{Z\left(1+(1+4 Z)^{0.5}\right)}{-1+(1+4 Z)^{0.5}}\right)^{\frac{0.5}{1-\rho}}}{\left(\frac{Z\left(1+(1+4 Z)^{0.5}\right)}{-1+(1+4 Z)^{0.5}}\right)^{\frac{0.5}{1-\rho}}\left(\frac{1-Z}{Z}-\left(\frac{1+(1+4 Z)^{0.5}}{Z\left(-1+(1+4 Z)^{0.5}\right)}\right)^{0.5}\right)+\frac{2(1+4 Z)^{0.5}\left(1+\left(\frac{Z\left(1+(1+4 Z)^{0.5}\right)}{-1+(1+4 Z)^{0.5}}\right)^{\frac{0.5}{1-\rho}}\right)}{-1+(1+4 Z)^{0.5}}}
$$

$$
g_{A}=\frac{\left(-1+\left(\frac{Z\left(1+(1+4 Z)^{0.5}\right)}{-1+(1+4 Z)^{0.5}}\right)^{0.5}\right)\left(E_{A}^{Y}-E_{A}^{X}\left(\frac{Z\left(1+(1+4 Z)^{0.5}\right)}{-1+(1+4 Z)^{0.5}}\right)^{\frac{0.5}{1-\rho}}\right)}{Z\left(\left(\frac{Z\left(1+(1+4 Z)^{0.5}\right)}{-1+(1+4 Z)^{0.5}}\right)^{\frac{0.5}{1-\rho}}\left(\frac{1-Z}{Z}-\left(\frac{1+(1+4 Z)^{0.5}}{Z\left(-1+(1+4 Z)^{0.5}\right)}\right)^{0.5}\right)+\frac{2(1+4 Z)^{0.5}\left(1+\left(\frac{Z\left(1+(1+4 Z)^{0.5}\right)}{-1+(1+4 Z)^{0.5}}\right)^{\frac{0.5}{1-\rho}}\right)}{-1+(1+4 Z)^{0.5}}\right)}
$$

$$
Y_{A}=E_{A}^{Y}-\frac{2(1+4 Z)^{0.5}\left(E_{A}^{Y}-E_{A}^{X}\left(\frac{Z\left(1+(1+4 Z)^{0.5}\right)}{-1+(1+4 Z)^{0.5}}\right)^{\frac{0.5}{1-\rho}}\right)}{\left(-1+(1+4 Z)^{0.5}\right)\left(\left(\frac{Z\left(1+(1+4 Z)^{0.5}\right)}{-1+(1+4 Z)^{0.5}}\right)^{\frac{0.5}{1-\rho}}\left(\frac{1-Z}{Z}-\frac{1+(1+4 Z)^{0.5}}{Z\left(-1+(1+4 Z)^{0.5}\right)}\right)^{0.5}\right)+\frac{2(1+4 Z)^{0.5}\left(1+\left(\frac{Z\left(1+(1+4 Z)^{0.5}\right)}{-1+(1+4 Z)^{0.5}}\right)^{\frac{0.5}{1-\rho}}\right.}{-1+(1+4 Z)^{0.5}}}
$$




$$
X_{A}=E_{A}^{X}+\frac{\left(1+\frac{Z\left(1+(1+4 Z)^{0.5}\right)}{-1+(1+4 Z)^{0.5}}-\left(\frac{Z\left(1+(1+4 Z)^{0.5}\right)}{-1+(1+4 Z)^{0.5}}\right)^{0.5}\right)\left(E_{A}^{Y}-E_{A}^{X}\left(\frac{Z\left(1+(1+4 Z)^{0.5}\right)}{-1+(1+4 Z)^{0.5}}\right)^{\frac{0.5}{1-\rho}}\right)}{Z\left(\left(\frac{Z\left(1+(1+4 Z)^{0.5}\right)}{-1+(1+4 Z)^{0.5}}\right)^{\frac{0.5}{1-\rho}}\left(\frac{1-Z}{Z}-\left(\frac{1+(1+4 Z)^{0.5}}{Z\left(-1+(1+4 Z)^{0.5}\right)}\right)^{0.5}\right)+\frac{2(1+4 Z)^{0.5}\left(1+\left(\frac{Z\left(1+(1+4 Z)^{0.5}\right)}{-1+(1+4 Z)^{0.5}}\right)^{\frac{0.5}{1-\rho}}\right)}{\left.-1+(1+4 Z)^{0.5}\right)}\right)}
$$

\section{Derivation of Reduced-Form Solution}

The first order conditions for player A (equations 6-8) under CES utility and ratio CSF imply:

$$
\begin{aligned}
& \left(X_{A} / Y_{A}\right)^{\rho-1}=\left(P / r_{A}^{Y}\right) \Rightarrow\left(Y_{A} / X_{A}\right)^{1-\rho}=P\left(h_{A}^{Y}+Z g_{B}^{Y}\right) / h_{A}^{Y} \\
& \left(E_{A}^{Y}-h_{A}^{Y}-Y_{A}\right)\left(\frac{Z g_{B}^{Y}}{\left(h_{A}^{Y}+Z g_{B}^{Y}\right)^{2}}\right)=\frac{h_{A}^{Y}}{h_{A}^{Y}+Z g_{B}^{Y}} \\
& \left(E_{B}^{X}-h_{B}^{X}-X_{B}\right)\left(\frac{Z h_{B}^{X}}{\left(h_{B}^{X}+Z g_{A}^{X}\right)^{2}}\right)=1
\end{aligned}
$$

Under symmetry, $P=1, h_{A}^{Y}=h_{B}^{X}=h, g_{A}^{X}=g_{B}^{Y}=g, X_{A}=Y_{B}, Y_{A}=X_{B}, E_{A}^{Y}=E_{B}^{X}$, and $E_{A}^{X}=E_{B}^{Y}$.

The symmetry information and equations (4) and (A.5)-(A.7) lead to:

$$
\begin{aligned}
& h=-Z g+\sqrt{Z^{2} g^{2}+\left(E_{A}^{Y}-Y_{A}\right) Z g} \\
& g=\left(\frac{-h}{Z}\right)+\sqrt{\left(\frac{h}{Z}\right)\left(E_{A}^{Y}-h-Y_{A}\right)} \\
& Y_{A}=\frac{\left(\frac{h+Z g}{h}\right)^{\frac{1}{1-\rho}}\left(E_{A}^{X}+E_{A}^{Y}-g-h\right)}{1+\left(\frac{h+Z g}{h}\right)^{\frac{1}{1-\rho}}} \\
& X_{A}=E_{A}^{X}+E_{A}^{Y}-h-g-Y_{A}
\end{aligned}
$$


Mathematica cannot solve equations (A.8)-(A.11) directly. Hence, we proceed with manual substitutions and algebraic manipulations, assisted by Mathematica on some intermediate steps.

To find the reduced-form solution for $h$, we substitute (A.9) into (A.8) and solve for $Y_{A}$ :

$$
Y_{A}=E_{A}^{Y}-\frac{2 h \sqrt{4 Z+1}}{\sqrt{4 Z+1}-1}
$$

We then plug (A.9) into (A.10) and again solve for $Y_{A}$ :

$$
Y_{A}=\frac{\left[E_{A}^{X}+E_{A}^{Y}-\sqrt{\frac{h}{Z}\left(E_{A}^{Y}-Y_{A}-h\right)}+h\left(\frac{1-Z}{Z}\right)\right]\left[\sqrt{Z h\left(E_{A}^{Y}-Y_{A}-h\right)}\right]^{\frac{1}{1-\rho}}}{\left[h+\sqrt{Z h\left(E_{A}^{Y}-Y_{A}-h\right)}\right]^{\frac{1}{1-\rho}}}
$$

Substituting the right side of (A.12) for $Y_{A}$ in (A.13) and solving for $h$ leads to equation (A.1).

To find $g$, we substitute (A.12) into (A.9) and rearrange to obtain a single $h$ term on the right:

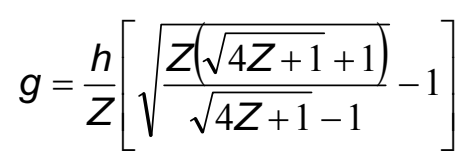

We then plug the reduced-form solution for $h$ into (A.14), which yields equation (A.2).

To obtain $Y_{A}$, we substitute the solution for $h$ into (A.12), which gives equation (A.3). To find $X_{A}$, we begin with equation (A.12), which implies:

$$
E_{A}^{Y}-Y_{A}-h=h\left(\frac{\sqrt{4 Z+1}+1}{\sqrt{4 Z+1}-1}\right)
$$

Plugging (A.15) into the right side of (A.11) leads to:

$$
X_{A}=E_{A}^{X}+h\left(\frac{\sqrt{4 Z+1}+1}{\sqrt{4 Z+1}-1}\right)-g
$$

Substituting (A.14) for $g$ and then the reduced-form solution for $h$ leads to equation (A.4).

Since the model is symmetric, the reduced-form solution for player $A$ also implies the reduced-form solution for player $B$, that is, $h=h_{A}=h_{B}, g=g_{A}=g_{B}, Y_{A}=X_{B}$, and $X_{A}=Y_{B}$. 